\title{
Urban Fragmentation and Discontinuity: Paranhos Case Study
}

\author{
Marcelo Altieri", Rodrigo Rojas \\ Faculty of Engineering, Oporto University, Portugal
}

Copyright $(02016$ by authors, all rights reserved. Authors agree that this article remains permanently open access under the terms of the Creative Commons Attribution License 4.0 International License.

\begin{abstract}
This paper aims to study design and urban planning tools able to create, enhance, transform or rescue the identity and cultural meaning of fragmented and discontinuous central/focal urban spaces. This work uses as a case study of Paranhos Parish in Porto, former peripheral area where, during the last fifty years has undergone relevant morphological and functional specialization changes. As a result, the region has lost its ability to define a central zone, with strong pulsar dynamic and able to structure the local character, making the territory a fragmented and discontinuous public space. Therewith, the cultural dimension and local meaning decrease significantly, been overshadowed by the heavy metropolitan road system. As it is a study focused on the design and urban planning, its methodology is supported by essays and empirical studies based on available built repertoire and designer cultural references. The narrative begins with a historical analysis, determining the evolution and current characteristics of the territory. Later, took place a study about the existing cores and the intrinsic urban dynamics developed, defining which has the most relevant social and cultural value - 'heart of the parish'. This step is complemented by a field research interviews - on the main local agents and how the development of urban dynamics happens. Then, using an empirical analysis, it sets up the main promoters of the fragmentation of space and what their intrinsic characteristics. Finally, it is presented a proposal in public space able to create, enhance, transform or rescue the identity and cultural meaning inside parish focus point.
\end{abstract}

Keywords Urban Fragmentation, Urban Design, Local Meaning, Urban Core, Livability, Urban Pulsar

\section{Introduction}

Urban spatial disruption phenomenon is directly linked with intensive and extensive development of urbanization and agglomeration, mainly occurring during the second half of the twentieth century [1]. To meet the growing metropolitan demand for mobility and activity/functionality new infrastructure networks were created specialized urban zones and functional clusters of greater complexity and capacity. Thus, new dedicated areas were settled to fit certain urban functions, such as social housing, technological and university centres, clusters of shopping malls, airports, all been strongly supported by infrastructure networks, such as highways, bridges complex and road intersections, underground rails, train terminals and etc. [2].

Following to this process, some locations were eventually fragmented, breaking both its physical structure as its social and cultural dynamics. The deployed infrastructure became urban obstacles, creating empty spaces of low or non-use places, requiring the local agent a new reality dynamics and cultural relevance. This gesture shows the ideology of order and rationalism that guided general public power territorialisation policies during the twentieth century. As an example, we can mention the High Line in New York, the 'Minhocão' in São Paulo, Porto highway 'VCI' and the intense dissemination of specialized zones and functional buildings.

This work uses the case study of Paranhos Parish in Porto. Former peripheral area where during the last fifty years has undergone significant morphological and functional specialization changes. In contrast to the concept of 'non-places' of Augé [3], it is argued that the intensive road structures and majority of educational mono function surfaces are not the source for a lower sense of community and belonging, but a consequence of urban spatial fragmentation. In this sense, Paranho's faces a poor capacity to define a central 'pulsar' location with a strong local character, able enough to structure the parish connections. Hence, the actual spatial form contributes for the development of a fragmented and discontinuous urbanization.

As this work is focused on urban design, its methodology is supported mainly by empirical studies based on author's repertoire and background and others cultural references. As a design plan, the working structure develops based on a 'macro' to 'micro' scale, analysing first all relations and connections between the local area and the whole Porto 
municipality. The narrative begins with a historical analysis, determining the evolution and current Paranho's territory characteristics. Later, actual urban dynamics are studied, trying to comprehend how it developed in the parish, defining its most centralized and cultural value. This step is complemented by a field survey on the main local agents and how to develop local urban dynamics. Then, through an empirical analysis, it is set up the main promoters of the urban fragmentation and what is their intrinsic feature. Finally, an intervention proposal is drafted in the public space in order to support the development of a new magnetic centre for Paranhos.

\subsection{Initial Remarks}

As will be shown below, during the intensive urbanization period - a century and a half, Paranho's failed to concretely define a focal structuring centre. It is considered that this inability results from a lack of urban appropriation by local community [4]. Therefore, denies that the functional specialization of the territory lead to weaker personal relationships, lack of identity and local memory. Urban infrastructures such as VCI highway, Asprela University Campus and São João Hospital are relevant to Porto's metropolitan area, being able to build links with society [5]. Figure 1 shows the highway dedicated 'infrastructure' area on Paranhos intersection near Paranhos Church Square. Then emerge one question: Whereas the urban spaces are socially produced, and so socially absorbed, which phenomena cause the urban space fragmentation and disruption?

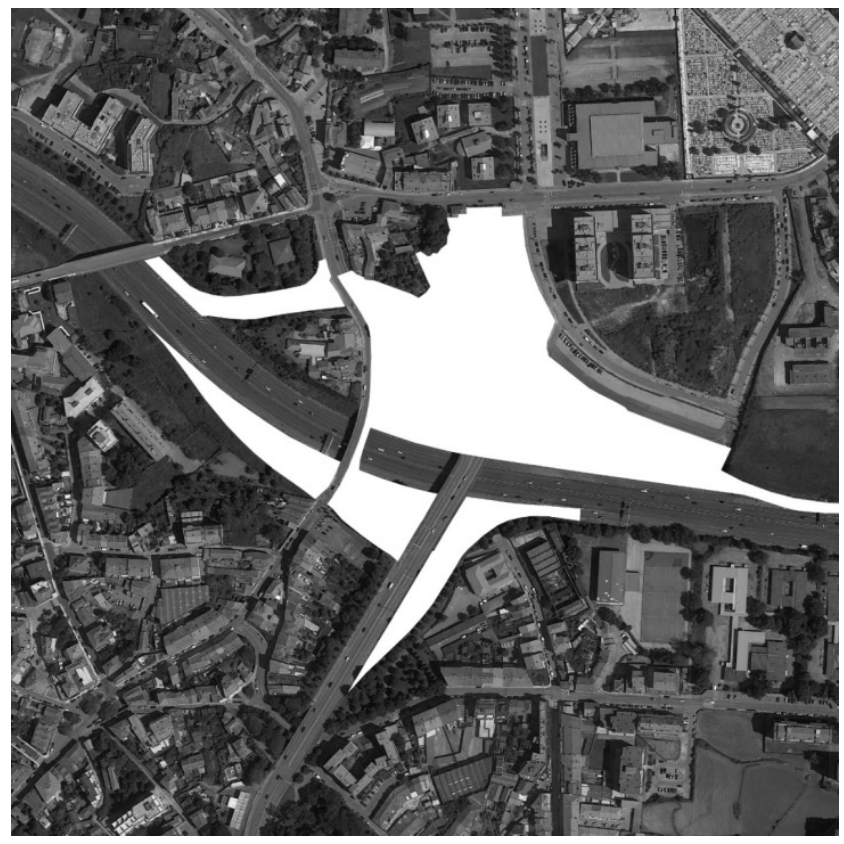

Source: Google earth

Figure 1. Integrators or shredders? Non-places or fragmented spaces?

To address this question, we seek to clarify Porto and the Paranhos parish urbanization process. This analysis occurs in double scale - metropolitan and local - as it is impossible to understand the social behaviour inside the 'partial' without the 'complete' area.

As an example, it is cited the urban transformation of Cais da Ribeira - Oporto - during the last two centuries. Initially, Cais da Ribeira social built space were exercised by an intense port activity, being occupied by trading boxes, goods, mules and pack animals, transportation machines and a wide range of workers. When Leixões Port was constructed, in the late nineteenth century assuming the lead role for freight transportation, it became an idle public space in the middle of a highly urbanized environment. Due to the low spatial regulation, the area became occupied by private cars especially during the second half of the twentieth century, when general workers income got higher and cars easily affordable. Currently, following new revitalization policies on Porto's central area and adaptation to tourist activities, the site become a supporting area for restaurants and coffee shops terrace in the Ribeira.

Thus, following will be conducted a brief study about Paranho's spatial social production evolution and its intrinsic characteristics and functions.

\section{Urban Social Production}

Still in the early nineteenth century, Porto held an urban structure with pre-industrial characteristics. Urbanized area was restricted to the current historic core, predominantly comprising the parishes of Sé, São Nicolau, Vitoria, Miragaia and Santo Ildefonso. Other urban areas were developed outside the realm of Porto, like Foz, near São João Batista Fortress and the central area of Matosinhos. The outskirts remained rural, accompanied by an urban settlement scattered along ancient roads.

At that time Paranhos not legally incorporated Porto municipality areas, a fact that would only run in the year 1837. The spatial social production had not been significantly altered, and the functions committed on the territory distinguished between agricultural fields and roads to the northern Portuguese kingdom.

With the advance of industrialization and population growth, urban scenario slowly changed. It is evident here the changing from the "old city" to "industrial city". Initially, the urban expansion took place along the ancient roads, such as: Rua de Monte Burgo (to Vila do Conde), Rua do Amial (to Braga) and Rua Costa Cabral (to Guimarães). For this reason, a greater concentration of buildings with typology similar to the recorded in the central core of Porto - volume, deployment on the ground and land uses, and the emerging of a nineteenth century urban pattern production developed along those three axis. As the urbanization process advance over urban axes arranged parallel in the municipal territory, the other internal areas still retained its agricultural function, preserving a low occupation density.

Also, new industrial plants were installed hospitals and health centres, new cemeteries and water distribution in the 
newly incorporated Porto's areas (especially Campanhã, Paranhos and Massarelos parishes). Paranhos stand out for Arca D'agua water fountain - major source of Porto's public water supply, Paranhos cemetery, the Campo Largo Lindo, 'Nova Empreza Industrial de Curtumes' (1920) - installed in Rua do Amial, Hospital Conde de Ferreira (Rua Costa Cabral) and Quinta do Covelo.

In the late nineteenth century, municipal authority opened the Estrada da Circunvalação - ring road, aiming to overtax all imported goods. One can make an analogy between the old medieval walls and the Ring Road - a new physical separation between Porto and its rural or outside area.

Supported by national and local economic development, the outlying parishes accelerate urbanization process and population density. This process was boosted by the arrival of new industrial workers with low income, seeking for affordable dwellings or empty lands. Already in the first decades of the twentieth century, Porto's suburban landscape was completely different and also well specialized. While Campanhã reported strong industrial development, Paranhos shows ability for public housing and working class dwellings - initially single family units and later collective blocks. During so called 'New State' political regime, new 'Economic Districts' were built, namely Azenha, Paranhos, Amial and Amial II, Costa Cabral and Outeiro and Regado. The massive residential buildings construction gave a strong dormitory neighbourhood character. It was possible due to the wide availability of undeveloped land next to the road corridors connecting the periphery and Porto central area - and the low land value and public property tax due to the lack of public infrastructure on those areas. Thus, Paranhos established itself as a territory with diffuse and dispersed spatial patterns, organized by well-defined radial axes, isolated housing blocks and some remaining farmland.

Spatial social production came to be changed again from the second half of the twentieth century. Powered by Porto industrial activity decline and accelerated suburbanization on outside municipality, Porto became a strong magnetic reference for its metropolitan context. The same socio-economic dynamics recorded internally in Porto during the nineteenth century was reflected in its new metropolitan scale. Thus, municipal urban space scale changed, getting new roads, public and private facilities of greater complexity and capacity and specialization of urban land. This period reports the change from the 'industrial city' to the 'modern city'.

Initially, Paranhos received the Escola Industrial do Porto (1952) facilities - currently ISEP - and the new São João Hospital (1959). During this period all new buildings found themselves isolated and scattered throughout Paranhos territory, with low occupancy rate inside potentially buildable land. During the 60's was built the Via de Cintura Interna (VCI), Porto's urban highway, connecting the Arrábida Bridge (Gaia) to Areosa (Av. Fernão Magalhães). Unlike other urban roads, VCI has technical and physical characteristics similar to the Americans urban 'Highways'.
As opposed to Estrada da Circunvalação, VCI was built 'inside' Porto, creating section and fragmentation on internal urban fabric. Similarly, along the highway a number of road junctions also provide a breakdown in urban structure, separating Porto urban space into two distinct parts: internal and external.

Finally, during the last three decades the new Asprela University Campus took place inside Paranhos. Except for the pre-existence of the Hospital São João and the Medicine Faculty, the 'first' school to settle in Asprela was Porto's Economics School in 1974, initiating the occupation of idle land that still plentiful in the region. One should also refer the construction of A3 motorway (Porto-Valença) and the Subway D line (Hospital São João - Santo Ovídeo). Figure 2 shows a concise four diagram graphic of Porto urbanization process, highlighting the three ancient roads and the two main infrastructure barriers, VCI and Estrada da Circunvalação.

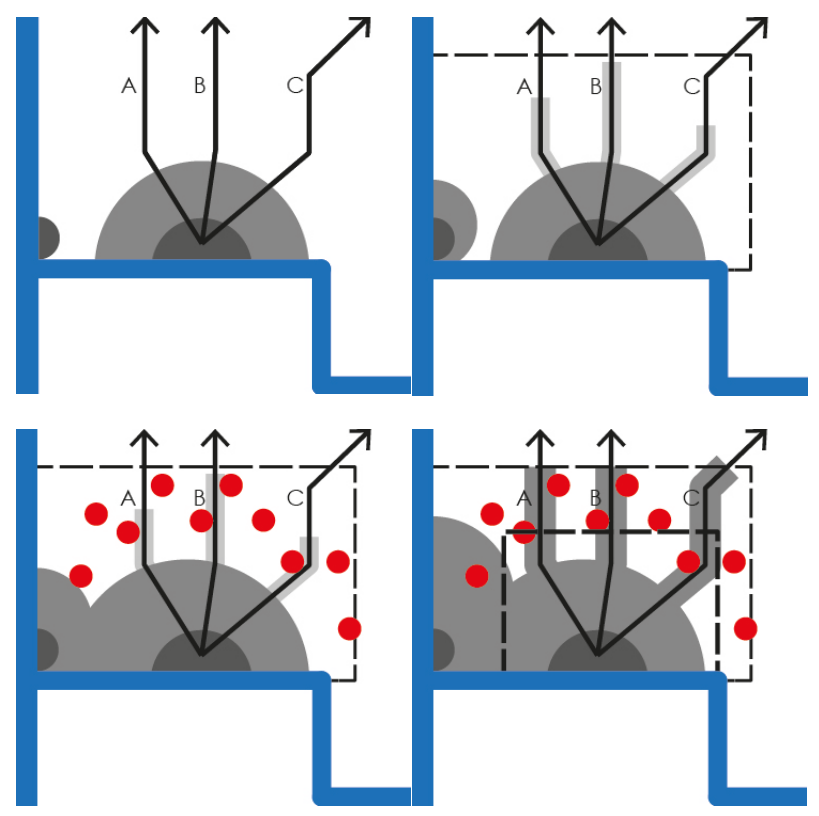

Source: Authors

Figure 2. Porto spatial social production development over XX century

\section{Finding Paranhos Central Pulsar}

Due to Paranhos wide territorial extension, several locations with high potential to assume the condition of 'central pulsar' were identified. Following will be presented the studied areas, a brief description of each individual case and which territory was chosen.

\subsection{Urban Axes: Monte Burgo, Amial E Costa Cabral}

The urbanization along the main Paranhos urban axes powered the development of a strong and complex social dynamics. As stated above, Monte Burgo, Amial and Costa Cabral streets suffered a relatively similar occupation process that recorded in Porto central area. So, along these 
routes there's a high density of dwellings, inhabitants, shops and everyday services, as post offices, banks agencies, butchers, bakeries and coffee shops and others shops in general. However, Amial Street stands out for miscegenation between different social classes and age groups, wider road and sidewalks - which allows one side parking, attracting more commuters and promoting local business - and a huge diversity of business and public interest services. Nearby the street, there are private dwellings and collective housing with early nineteenth century typology and other collective 70s typology, forming a diverse and heterogeneous social characteristics population. Likewise, the proximity to ISEP and Asprela University Campus allows the integration among young people, adults and seniors, catalysing region's social diversification. There are also two high schools - private and public, kindergartens, hotels and churches.

\subsection{Gardens, Squares and Public Areas: Jardim Da Arca D'agua (Praça 9 de Abril), Largo Da Igreja De Paranhos}

During the nineteenth century and the early twentieth, Paranhos played an important urban technical infrastructure role: one of the main public water supplying system for fountains. Among the existing sources, Arca D'agua garden stood out for its capacity and water quality. Initially, a new underground storage systems and distribution galleries Cedofeita region and Boavista were built beneath the site. As urban sprawl approached to the region, its single functional role and geometry were altered. At the beginning of the twentieth century Arca D'a agua landscape had a several change, owning a Square status and setting a new order for urban occupation on the surroundings for the following years.

Road and pathways from Arca D'agua lead to Porto central area (Rua do Vale Formoso), Largo de Lindo Campo Largo (Rua Costa e Almeida) and Paranhos Church Square (Rua Delfim Maia). On the other hand, the other square or gardens also communicate themselves through Rua da Igreja de Paranhos, forming a geographical triangulation. This reference morphological condition recurs in various urban models and is present from smaller scale clusters - religious triangle of São Paulo Paraitinga - to the great monumental perspectives of Versailles, Washington and Buenos Aires.

Paranho's reference triangle is also home of Paranhos Church Square, chosen location to play the role of 'central pulsar'. The similarities between the Square and the parish go far beyond simple sharing the place name. As well as the parish, the location social urban context changed radically over the last century, showing the transition between the 'old town' and the 'modern city'.

For decades, there was low presence of the public power in the region, leaving Paranhos Church Parish acting as a primary social institution in the neighbourhood. For its implementation, were choose a high area overlooking
Asprela agricultural fields and with good access to Campo Lindo, Arca D'agua and Amial. First, as a result of population growth and Porto urban expansion to the peripheries, the adjacent lands intensify the urbanization, strengthening referential importance of urban space and its centralizing capacity.

However, the VCI prevented physical communication between Jardim da Arca D'agua and Largo de Campo Lindo (also the visual continuity of Rua do Amial axis) and intensified traffic of motor vehicles in Paranhos Church Square. The space that was formerly occupied by people and community activities (activities similar to those currently practiced in Jardim da Arca D'agua) was occupied by cars and metropolitan mobility systems.

Unlike Augé 'non-places' concept, this process does not mean a loss of identity and social condition, but rather a change in its urban function and social appropriation of urban space. Similarly, the occupation of idle land of Asprela by a single activity - education - it is not an emptying of urban social dynamics, as advocated by Augé.

\subsection{Metro Stations: Hospital São João, I.P.O. E Polo UniversitáRio}

Paranhos is served by Porto Metro D Line - Santo Ovídeo/Hospital São João, and three main stations are located inside demarcated Asprela University Campus. At first glance, it appears that both situations shares a wide and plenty public space, with the potential to promote the emergence of new social dynamic. However, while establishing a strong relationship between the town and the entire Porto metropolitan context, the stations are unable to build a solid narrative enough to play a leading role and urban reference.

Hospital São João Station has a strong metropolitan mobility character, offering a rich urban interface between different modes of public transportation. Apart from the existence of Porto's most important Hospital, it is placed on a wide urban area facing Estrada da Circunvalação and an exclusive bus lane with several stops and feeding lines. This situation breaks any effort to establish a reasonable permeability between the Station and the surroundings and a central focus capacity.

In the case of Polo Universitário Station, it is placed beneath a wide open area with a number of vacant plots and mono functional buildings. This scenario creates a rough visual and physical permeability with no potential to establish any focusing role or pulsar centrality.

Beside the two mentioned before, IPO Station seems to have more potential for leading some centrality. The Station is placed next to a medium size shopping mall, with a supermarket and a low budged hotel. Through ISEP and University Portucalense, commuters can reach Azenha collective houses and Rua do Amial. It is remarkable that IPO Station gather the most relevant aspects for being the pulsating Station, but it is insufficient to be defined as the Parrish central pulsar. 


\section{Design Basics}

The proposed design plan for Paranhos Church Square has the following strategy: approach the physical and functional components of the built urban space. In this way, we seek to reduce the effects of territorial fragmentation imposed by the VCI and create a space that works the transition between the urban area and the mono functionality educational zone (Asprela University Campus).

First, it is intended to reduce the impact, noise visual and physical, played by the urban express highway. Therefore, it is proposed to channel VCI between Rua Delfim Maia and Rua Faria Guimarães, allowing visual and physical space continuity and creating new urban 'land'. This model is inspired by the Ronda de Dalt in Barcelona. As well as the VCI, the expressway surrounds Barcelona urban area alternating between high and low densely urbanized areas. In excerpts with high urban concentration the route goes down and offers some sort of public facility to street level. Running this model allows to 'create' new potentially buildable land, which, from its full employment, reduced sense of visual and functional discontinuity.

Easing the physical impact of the VCI is not enough to revitalize Paranhos Church Square. There's a need to change the function of urban space. Thus, its characteristic of road access to the VCI is disqualified, returning the space taken by streets to pedestrian and community activities. Wherefore, it is proposed that access to VCI and Faria Guimarães Street be shifted to Rua Alfredo Allen axis, relieving the intense flow of vehicles in Paranhos Square. Also it proposes the removal of walls and fences of private alignment of the Church of Paranhos, integrating the building with the 'new' Square that opens, and greater physical permeability between Square, university residence and the public open area of metro station.

This work has no intension on discussing the ideal model of occupation on new urban land 'created'. As the spatial social produced of Paranhos is diverse and dispersed, it is possible to defend numerous types of occupation, being very personal and with a high degree of technical detail discussion. So, beside the morphology and geometric shape, it was conduced a simple exercise about what kind of use and function the new empty area could develop. Figure 3 and 4 shows the two most relevant options, a 'regular' urbanization and a new public park over VCI area. Regarding that a stronger relationship between Paranhos Church and Campo Limpo Square and Jardim da Arca D'agua consist a relevant issue, the first option seems to work a better behaviour. As suggested by the graphic composition, filling all voids with urbanization decrease the visual impact played by the emptiness and enhances space continuity. Figure 3 is composed by a compound of some crop images from Matosinhos south area (regular rectangular urbanized pattern $-85 \times 180 \mathrm{~m}$ ) and a crop image from Parque da Cidade. Figure 4 is only composed by Parque da Cidade cropped image.

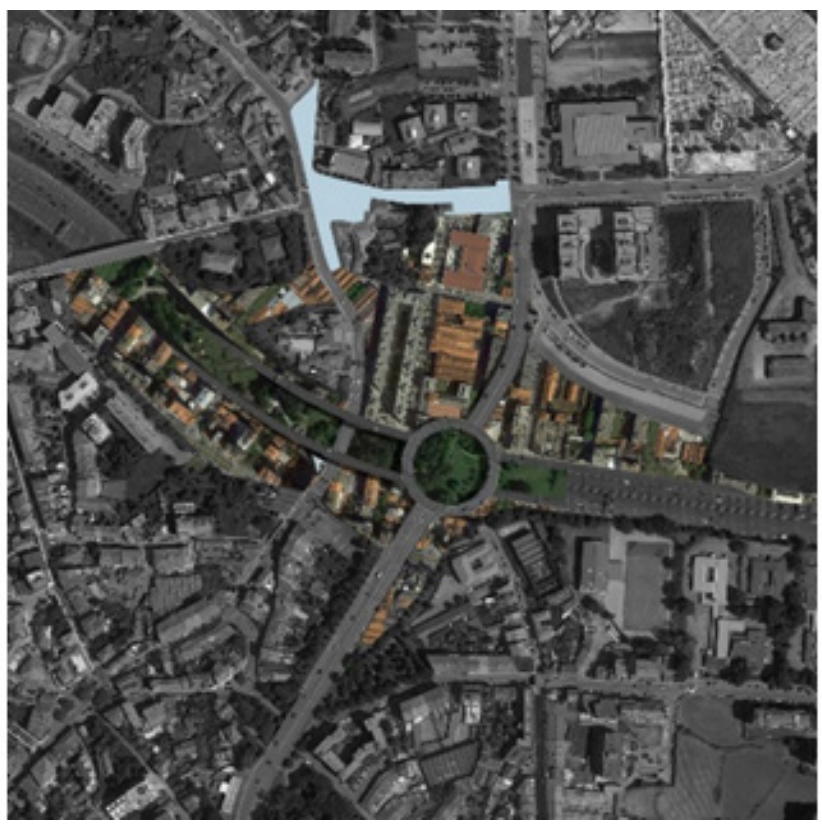

Source: Authors

Figure 3. Regular' urbanization

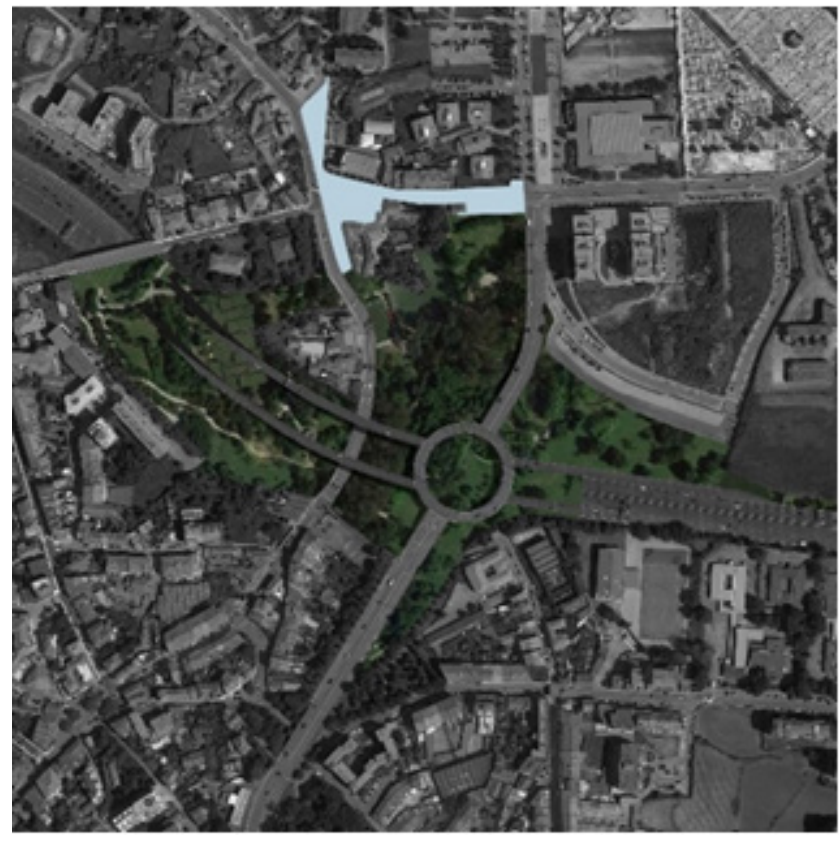

Source: Authors

Figure 4. New public Park

Thus, the final proposal should look to 'sew' the spaces between the Paranhos Church Square, Jardim da Arca D'agua, Campo Lindo Square and Asprela University Campus and return the formerly pedestrian urban space and filling all voids that decrease physical and visual connection. The design plan also assumes the need for a more functional and visual approach between the Paranhos Square and Asprela area.

Following, a brief description of the proposed design plan for Paranhos Church Square, some technical drawings and all main structures or measures to be taken. 


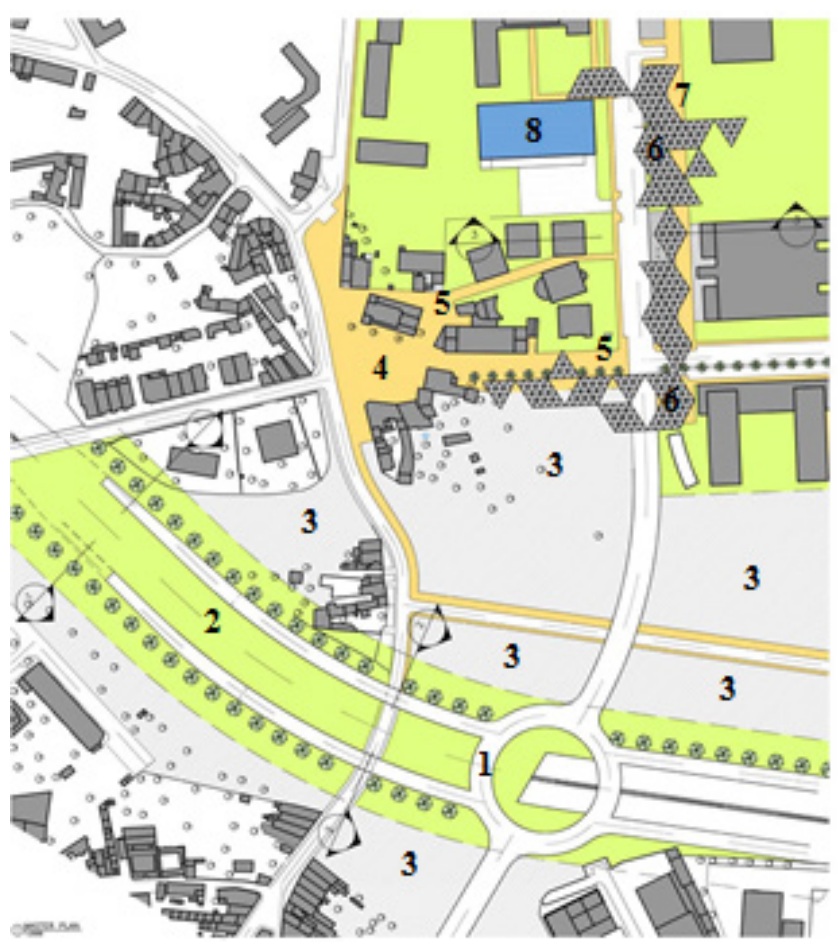

Source: Authors

Figure 5. Proposal master plan

\section{Design Proposal}

The new design proposal that seeks to 'create' and enhance a new pulsar centrality on Paranhos it is represented by figure 5 . The master plan - figure 5 - shows the design proposal, fitting all relevant changes on the chosen area and nearby surroundings. As this work aim only to provide some conceptual design basis, there are no further detailing drawing. Some samples and existing references will be used to give a more sharp and precise idea about the detail design proposal and materials to be used.

The new pulsating urban centre of Paranhos Parrish consists of the full extent of Paranhos Church Square till the intersection between Rua Alfredo Allen and the Rua Dr. Manuel Pereira da Silva. Through this proposed design interventions, comprising Paranhos Church Square and some nearby surrounding areas, emerge a chance to increase the local potential and strength site memory, social dynamics and build a meaningful and magnetic spot on the neighbourhood (Parrish) following a brief description of all design proposals.

\subsection{New Highway Intersection}

As stated previously on chapter 4, setting up a new arrange for the existing traffic management and road infrastructure performs a crucial role on providing fundaments for the development of a new central pulsar for Paranhos. Attempting to reduce the urban highway visual and physical barriers it is proposed an alternative road intersection structure comprising the VCI highway, Rua Faria Guimarães (way to Porto downtown) and Asprela University Campus major access. The new road intersection will be accomplished through a partial channelling of VCI (between Delfim Maia Bridge and Faria Guimarães Bridge) and a by passing all traffic distribution to a new roundabout. This initiative rearrange and replace the existing road connection of Paranhos intersection, removing a huge amount of roads, tunnels and bridge that support a complex multiple route choice. Thus, this initiative enables to decongest Rua da Igreja de Paranhos, partially Rua Dr. Manuel Pereira da Silva, promote and enhance traffic circulation throughout the area maintaining efficiently the existing multiple route choice and decrease physical and visual barriers.

The roundabout it is placed following the intersection of VCI and Rua Faria Guimarães road axis. Composed by three lanes, each one with three meters and a half, a protected area with one meter on each side and an outer radius forty-two and a half meters, a fine traffic circulation is granted inside the new proposed road intersection. Adopting three lanes allows performing one emergency lane, feeding São João Hospital with an express ambulance alternative route.

All highway access to the roundabout have two lanes and $6 \%$ slope, while Rua Faria Guimarães have four lanes and $7 \%$ of slope, allowing $60 \mathrm{KM} / \mathrm{H}$ speed on all routes and access .The new road infrastructure design proceeded to extent Rua Alfredo Allen width in seven meters in western direction without affecting any existing buildings or spoiling private property: This action seeks to provide a total of four traffic lanes - two for each direction mirroring the same traffic width and configuration existing along Rua Faria Guimarães axis. To ensure these initiatives a removal of one parallel parking on Rua Alfredo Allen must be considered, counting the loss of 29 public parking spaces.

Adopting this new traffic system and others infrastructure, necessary conditions to remove heavy vehicular traffic from Paranhos Church Square will be created, allowing a deeper design intervention that deals more with social and cultural dynamics.

\subsection{Public Open Park}

As a result from VCI channelling and rearranging all roads access, some 'new' land emerge inside the existing urban fabric. Those lands are divided into two categories, non-buildable and buildable. To avoid noise pollution, intensive traffic disturbs, light pollution and even some legislation issues, all land located between the two roundabout access as well as a ten meters width strip along those roads will be set as non-buildable land. So, inside this area will be prohibited to develop any kind of building addressing housing, offices, shops and industries. This land will remains under public domain and will give a place for 
an open public Park, allowing the continuous development of urban fabric and spatial permeability.

The new public Park will be equipped with leisure and physical activities furniture, sports facilities and a landscape design that integrate all functions and the existing building surroundings.

\subsection{New 'Land' with High Urban Potential}

Taking advantage from the brief land occupation exercise on chapter 4 (figure 3 and 4), it is determined how all remaining land (where 'regular' buildings can occur) should be developed. For this area is intended to set a 'regular' urbanization, free market-led development comprising mainly daily urban functions, both social and private housing or student residences, shops and services. By adopting this concept, all lands will be given to private development and there is no concern about any predefined design constrain.

\subsection{Paranhos Church Square}

The follow-up steep to traffic reduction and road infrastructure amenities, structuring land uses and urbanization process is actually to provide an urban design proposal for the chosen area of Paranhos Church Square. As the heavy traffic circulation was removed from Rua Dr. Manuel Pereira da Silva and it intersection with Rua da Igreja de Paranhos, it is proposed to prohibit vehicles traffic along the street's first section. Both sidewalks must be integrated by levelling the road, replacing finishing material to make it homogenous. Oddly from the existing site, this attempt to create a real public space to host Paranhos Church. Also, strong enough to boost local development and attract private investment on surroundings.

Another relevant issue is the removal of a small wall that surrounds Paranhos Church. This action promotes a higher physical and visual integration between the Church and the immediate neighbourhood though the 'new' square created, enhancing its initial social value.

Such design measures could be found on many others places around Europe, mainly nearby Churches and historical squares. In general, this kind of new urban spaces gives support to perform small events, usually promoted by the local actors or the Parrish organization. Thus, a wide free area is needed and must be ensuring enough space for a huge diversity of events and folk's activities. By adopting this concept, new urban furniture, such as benches, bins, public lighting and water fountain, should be placed considering both daily and special events needs and constrains.

It is important to mention that for loading and unload services for restaurants, shops and religious events, it is proposed the installation of anti-parking system, allowing freight vehicles to access buildings and controlling the traffic in the levelled area.
To extend Paranhos Church Square as much as possible in the direction of Asprela University Campus, 'sewing' a strong relation - visually and physically - between both areas, a line of small/medium size trees took place following the existing south sidewalk alignment of Rua Dr. Manuel Pereira da Silva. All trees are set with a regular distance rhythm, about 10 meters, going from the pedestrian section till the traffic open section. Though, visual and physical permeability between Asprela and Paranhos Church are increased through continuity.

\subsection{Paths and New Connections}

To enhance visual and physical permeability it is proposed to open a new pedestrian path connecting the backs of Paranhos Church and University Rooms/E-learning café. For so, one vacant and apparently abandoned building should be demolished. Hence, not only allows a better mobility within region but increase local relationship and approximate a well socially diverse population. Initially, most existing buildings are kept as well as their functions.

\subsection{Square Cover and Sun Shading}

Another measure to enhance and promote visual and physical permeability between Asprela and Paranhos Church Square is a proposal for a cover surface along Rua Alfredo Allen subway station open area, especially between Polo Universitário station entrances. The proposed surface will cover a large area, mostly sidewalks, walking areas as described in the master plan drawn. It will be composed of a light steel structure with wooden components regarding to not fully close the ceiling, offering sometimes fully open areas and other partially closed, with some framing for sun shading. An overall free height of seven meters allows the performance of many events as well as sheltering some daily activities and new social dynamics.

By adopting this concept, some daily social routines and dynamics from the urbanized Paranhos area are mixed with the mono-functional educational activity from Asprela University Campus, building a place for cultural and social exchange. If supported by some permanent activities, this place can assume an integrative role on the surroundings.

\subsection{Small Shops}

To enhance social dynamics and promote the development of a new 'urban' activity in Asprela University Campus, it is proposed to establish simple Kiosks under the covered area in Rua Alfredo Allen. The Kiosks structures should be based on naval container dimensions or may be slightly bigger or smaller depending on usage. This kind of infrastructure is pretty common on some highly dense urban areas, such as Tokyo, Xanghai, New York and others places, providing several layout options and technology to support a big number of activities. 
For Polo Universitário station it is proposed a diverse functional occupation, admitting shops, cafes, small restaurants - fast food or any other kind of cooking that don't demand high exhaustion - and any other daily activity. Cafes and small restaurants should be allowed to occupy some nearby areas with tables and chairs, providing a reasonable space to work and receive costumers.

There's no interest in overcrowding the covered station 'plaza' as well as setting no rules for the Kiosk structure. The number of Kiosks will attempt to ensure a good pedestrian circulation, taking in consideration both shops/restaurants costumers and Asprela Campus as well as Metro Station commuters, and the 'public' space occupied by tables and chairs. It will also provide a clear and safe passage to Metro Station stairs and all educational buildings located around. Concerning about the Kiosk physical structure and finishing material or individual customizing, a structural template model should be follow to ensure some regularity on Kiosks shape. All other customization and finishing materials must be allowed, giving to all owners the ability to promote their trademark as expected.

\subsection{Parking Building}

Finally, it is proposed to build a new parking garage to replace the existing uncovered parking lot between the Faculty of Psychology and the University Residence, all public parking spaces removed due to Rua Alfredo Allen widening and enhance site existing capacity. The new building should have a volume with low visual impact and about six meters high, with three working slabs - two indoor and the latest uncovered. Currently, in the area there are two uncovered parking, a formal, with 71 places available and another informal with about 50 places, totalling 121 parking places. Through the new landscaping and implementation of the garage building 345 parking spaces will create, increase the current number by 224 . This measure seeks to reduce the number of vehicles irregularly parked in the area, offer better conditions for incoming cars and support for Porto's subway network and commuters.

If more parking places appear to be necessary two alternatives emerges as possible solutions. Firstly, an underground parking can be constructed beneath the proposed parking building. So, it is recommended that the structural plan consider this further expansion. Another solution is to occupy the existing open parking lot from Dental Medicine School (actually with 73 parking places). It should consider another low visual impact building with no more than six meters height.

\section{Conclusions}

Based on understanding the pattern of spatial social production and all agents for urban space fragmenting, the final design intervention proposal seeks to define Paranhos Church Square as the central pulsar and a structuring Paranhos player. Using urban design as basis tools, we recommend two main measures and actions to enhance the urban space quality and encourage the development of integrated urban dynamics and potential new local activities. The first measure is to reduce the impact from the poor quality expressway access and move the heavy traffic from the Paranho's Church Square to the new area of Polo da Asprela. This action seeks to manage the congestion in Paranhos area, creating a favorable environment for social network and exchange. The second seeks to develop several supportive infrastructures to encourage a new social interaction between Paranho's Church and the Polo da Asprela area.

However, changing the landscape and proposing new activities should generate impacts on each member of the society, causing new identity connections, memories, and social ties. This work regards precisely this dichotomy between the urban fragmentations and the strengthening of the community socio emotional consciousness. As recent studies suggest $[6,7,8]$, promoting quality of life and encouraging social interaction should reduce the sense of isolation and act as a catalyzer for spatial social production and inclusive of urban spaces.

\section{REFERENCES}

[1] Lefebvre, H., 2003. The Urban Revolution, U of Minnesota Press.

[2] Graham, S. \& Marvin, S., 2001. Splintering Urbanism: Networked Infrastructures, Technological Mobilities and the Urban Condition, Routledge.

[3] Augé, M., 2010. Não-lugares, PAPIRUS.

[4] Villaça, F., 2012. Reflexões sobre as cidades brasileiras, Studio Nobel.

[5] Lynch, K., 1960. The Image of the City, MIT Press.

[6] Badland, H. et al., 2014. Urban livability: emerging lessons from Australia for exploring the potential for indicators to measure the social determinants of health. Social science \& medicine (1982), 111, pp. 64-73.

[7] De Haan, F. J. et al., 2014. The needs of society: A new understanding of transitions, sustainability and livability. Technological Forecasting and Social Change, 85, pp. 121132 .

[8] McCrea, R. \& Walters, P., 2012. Impacts of Urban Consolidation on Urban Livability: Comparing an Inner and Outer Suburb in Brisbane, Australia. Housing, Theory and Society, 29(2), pp. 190-206. 